\title{
Developing a high capacity axis translation apparatus for gas shale testing
}

\author{
Jinwoo Kim ${ }^{1, *}$, Alessio Ferrari ${ }^{1}$, Russ $\mathrm{Ewy}^{2}$, and Lyesse Laloui ${ }^{1}$ \\ ${ }^{1}$ Laboratory of Soil Mechanics, Swiss Federal Institute of Technology Lausanne (EPFL), Lausanne, Switzerland \\ ${ }^{2}$ Chevon Energy Technology Co., Richmond, CA, USA
}

\begin{abstract}
Gas shales are usually partially saturated due to hydrocarbon generation and often have a low insitu degree of saturation less than $40 \%$. During stimulation, substantial fluid imbibition into the formation occurs due to high suction. Recent research on these shales showed that changes in saturation strongly affect the strength and elastic properties, as well as their hysteretic behavior. To date, most experimental methodologies were based on total suction control by the vapor equilibrium technique. We postulate that the more representative in-situ conditions can be reproduced by capillary pressure control using the axis translation technique. The main challenge, however, is that the capillary pressure range is limited and far from sufficient to bring gas shales to partially saturated conditions. This paper introduces our recent progress in developing a high capacity axis translation apparatus for gas shales testing. Four high air entry value (HAEV) filter candidates were tested and evaluated for their performances and suitability.
\end{abstract}

\section{Introduction}

Gas shales are usually partially saturated with the pore space filled with brine and hydrocarbon (liquid and/or gas). Typical in-situ degree of saturation ranges between 15 and $40 \%$ [1]. The presence of immiscible fluids especially hydrocarbon gas and brine - in the nanometer scale pores generate high capillary pressure [1]. At low saturation, water adsorption onto the clay surface also prevails [3], leading to very high in-situ matric suction. Besides, brines in these shales often have appreciable salinity and osmotic suction [4].

The two suction components, matric suction and osmotic suction, then sum up to several dozens of MPa of total suction and act as a strong driving force for water imbibition during stimulation. Numerous field evidence supports this idea; more than half of the water injected in the well is not recovered during flowback operations [5,6]. Not only is this uneconomical, but subsequent changes in saturation may also cause shale stability problems [7] and reservoir damages [8].

In this regard, Ferrari et al. [9] developed a testing set-up and experimental methodology based on total suction control to study the elastic behavior of partially saturated gas shales. Imbibition and desiccation processes were reproduced by the vapor equilibrium technique [10]. Various total suction levels (or relative humidity) were attained by changing saline solutions in a closed system. External stress was applied by uniaxial compression in the direction perpendicular to bedding.

The experimental results in Ferrari et al. [9] showed that partially saturated conditions strongly affect the elastic and strength properties. In other studies, the same authors also studied the non-linear elastic response influenced by the sliding crack mechanism [11] and the mutual influence between the water uptake and the volumetric deformation [12].

It is certainly appreciated that total suction control by the vapor equilibrium technique allows replicating a wide range of saturation states. In general, this technique can control total suction within the range between 4 and $400 \mathrm{MPa}$ [10]. This was a prerequisite for gas shale testing and successfully adopted in the studies above $[9,11,12]$. The limitation, however, is that the air pressure remains atmospheric, which is not representative of the in-situ reservoir conditions.

The axis translation technique [13], on the other hand, can control the pressures of two immiscible fluid phases within positive ranges. Also, both axial and radial confining stresses can be applied in a triaxial cell. We postulate that this is more representative of the in-situ stress conditions in unconventional shale gas reservoirs, where pore pressure is elevated from the hydrostatic pressure, and stress magnitudes tend to be close to isotropic [14].

The main challenge of adopting the axis translation technique for gas shale testing is that the capillary pressure range is limited and far from sufficient to bring gas shales to partially saturated conditions. Here, it should be noted that the upper limit of capillary pressure solely depends on the gas breakthrough pressure (or air entry value; AEV) of the filter - thus, an advanced filter with a high gas breakthrough pressure must be sought.

We introduce our recent progress in developing a high capacity axis translation apparatus for gas shale testing. First, a brief background on capillary pressure

Corresponding author: jinwoo.kim@epfl.ch 
and the axis translation technique is presented. Then, an experimental campaign to evaluate the performance of filter candidates is introduced. To this end, the suitability of four high air entry value (HAEV) filter candidates for gas shale testing will be discussed.

\section{Background}

\subsection{Capillary pressure}

In general, suctions of geomaterials represent the negative potential of water and have been universally used to describe partially saturated conditions. Total suction is the sum of matric suction and osmotic suction:

$$
\psi=s+\pi
$$

where $\psi$ is total suction, $s$ is matric suction, and $\pi$ is osmotic suction. Matric suction is associated with the matrix of the geomaterial and includes capillary, osmotic, and electrostatic mechanisms [15]. Matric suction can be decomposed into two components:

$$
s=P_{c}+P_{d}
$$

where $P_{c}$ is capillary pressure and $P_{d}$ is disjoining pressure corresponding to the adsorption [16].

Capillary pressure rises when two immiscible fluids, for example, brine and hydrocarbon gas, are in contact in the pores. The difference between pore gas and water pressure can be computed by the Young-Laplace equation:

$$
P_{c}=P_{g}-P_{w}=4 T \cos \vartheta / d
$$

where $P_{c}$ is the capillary pressure, $P_{g}$ is the pore gas pressure, $P_{w}$ is the pore water pressure, $T$ is the surface tension of water, $\vartheta$ is the contact angle, and $d$ is the pore diameter. By combining a water retention curve of a gas shale sample [9] and contact angle measurement data [17], a first-order approximation of in-situ capillary pressure in gas shales would be $10 \mathrm{MPa}$ or higher.

\subsection{Axis translation technique}

First suggested by Hilf [13] in the 1950s, the axis translation technique has been comprehensively discussed as a laboratory technique to control matric suction [18-21]. It provided an experimental basis for the Bishop's effective stress equation for unsaturated soils [22] and was also successfully adopted to study the independent stress variables [23].

Despite the popularity, there have been some criticisms regarding its validity to test unsaturated soils. The two main points are: 1) it is not representative of the field condition of atmospheric air pressure and negative water pressure [24] and 2) it is not clear if the gas phase is continuous at nearly saturated states [18]. Both of these concerns are relieved if it were used to test gas shales. First, it does represent positive in-situ fluid pressures. Second, nearly saturated states are not of interest because of the low in-situ degree of saturation.
The upper limit of capillary pressure is bound by the gas breakthrough pressure of the filter. In other words, capillary pressure can be increased within a range that the filter remains saturated by capillary sealing. Conventional HAEV ceramic discs that are commercially available usually have single dominant pore sizes larger than $200 \mathrm{~nm}$ and provide approximately 1.5 $\mathrm{MPa}$ of maximum capillary pressure.

A critical issue regarding the performance of the filter is the gas diffusion across the filter. Gas will dissolve into the water from one side, diffuse through the water phase by the concentration gradient, and come out as bubbles from the other side because of the solubility limit $[10,25]$. The diffused gas bubbles will then lead to an increase in water volume, complicating the tracking of water exchange. Several authors measured the diffusion flow rate [25-27] and suggested elevating the applied water pressure to reduce the diffused gas volume [26] or recommended frequency of flushing [27].

\subsection{Non-ceramic filters}

Some researchers adopted new filters instead of a ceramic disc in the axis translation apparatus (Table 1). Romero [10] stated that the upper limit could be enhanced to $7 \mathrm{MPa}$ with cellulose acetate (CA) membranes and later published experimental results on compacted clay with his colleagues [28,29]. Nishimura et al. [30] and Hong et al. [31] used polyethersulfone (PES) membranes but within a lower range of capillary pressure. Sharing the same principle, there has been a remarkable advance in developing an ultra-high capacity tensiometer by adopting a nanoporous glass $[32,33]$.

Table 1. List of literature that used non-ceramic filters

\begin{tabular}{|c|c|c|c|}
\hline References & $\begin{array}{c}\text { Maximum } \\
\text { capillary } \\
\text { pressure }\end{array}$ & $\begin{array}{c}\text { Filter } \\
\text { material }\end{array}$ & Type \\
\hline$[28,29]$ & $14 \mathrm{MPa}$ & $\begin{array}{c}\text { Cellulose } \\
\text { acetate }\end{array}$ & Oedometer \\
\hline \multirow{2}{*}[30]{} & $40-60 \mathrm{kPa}$ & $\begin{array}{c}\text { Acrylic } \\
\text { copolymer }\end{array}$ & \multirow{2}{*}{ Oedometer } \\
\cline { 2 - 3 } & $\begin{array}{c}100-250 \\
\mathrm{kPa}\end{array}$ & PES & \\
\hline$[31]$ & $350 \mathrm{kPa}$ & PES & Triaxial \\
\hline$[32,33]$ & $7 \mathrm{MPa}$ & $\begin{array}{c}\text { Nanoporous } \\
\text { glass }\end{array}$ & Tensiometer \\
\hline
\end{tabular}

A few works $[28,29]$ reported the use of a CA membrane with maximum capillary pressure (14 MPa) higher than that of conventional ceramic discs (1.5 $\mathrm{MPa}$ ). Indeed, this was a groundbreaking advance and would be more than sufficient to test shales and gas shales. However, information on permeability, diffusion coefficient, and deformability, all of which are necessary to characterize a new filter was not documented.

CA membranes are most likely not suitable for a long experiment since they are subject to degradation and bacteria growth. In comparison, PES membranes are more resistant and show better long-term performance 
[34]. Since gas shale testing generally requires a long time because of the low permeability, PES membranes would be preferred over CA membranes.

\section{Experimental Campaign}

\subsection{Filter candidates}

Four filter candidates and their specifications pertinent to the axis translation technique are summarized in Table 2. Note that Ceramic Discs A and B were tested by [35]. Both Ceramic Discs have pore smaller pore sizes compared to the conventional ones, while Ceramic Disc $\mathrm{B}$ has a thin layer of $\mathrm{Al}_{2} \mathrm{O}_{3}$ coating on top. Membrane $\mathrm{XT}$ is an Ultrafiltration (UF) PES membrane originally used for filtration. They are supplied in flat sheets; thus, 30 die-cut membranes were stacked and sandwiched by two porous discs. Shale Disc was cut from a low porosity shale core extracted from $3.3 \mathrm{~km}$ depth. The thicknesses found in the brackets indicate compaction due to confining stress (Membrane XT) or expansion due to swelling (Shale Disc). Porosity values were estimated by mercury intrusion porosimetry (Ceramic Discs), by measuring the water content after saturation (Membrane XT), or by water immersion porosimetry [36] (Shale Disc). The largest pore sizes were determined from the pore size distributions obtained by MIP (Ceramic Discs and Shale Disc) or are a nominal value (Membrane XT). The maximum capillary pressures were calculated by Eq. (3), assuming 0 degrees of contact angle.

Table 2. The tested filter candidates

\begin{tabular}{|c|c|c|c|}
\hline & $\begin{array}{c}\text { Ceramic Disc } \\
\text { A \& B [35] }\end{array}$ & $\begin{array}{c}\text { Membrane } \\
\text { XT }\end{array}$ & Shale Disc \\
\hline Photo & 43 & 43 & 43 \\
\hline $\begin{array}{c}\text { Diameter } \\
{[\mathrm{mm}]}\end{array}$ & 5 & $5.8(4.3)$ & $5.7(5.8)$ \\
\hline $\begin{array}{c}\text { Thickness } \\
{[\mathrm{mm}]}\end{array}$ & 0.20 & 0.15 & 0.10 \\
\hline $\begin{array}{c}\text { Estimated } \\
\text { porosity [-] }\end{array}$ & 60,70 & 14 & 6 \\
\hline $\begin{array}{c}\text { Largest pore } \\
\text { size [nm] }\end{array}$ & $4.8,4.1$ & 20 & 48 \\
\hline $\begin{array}{c}\text { Maximum } \mathrm{P}_{\mathrm{c}} \\
\text { (theoretical) } \\
{[\mathrm{MPa}]}\end{array}$ & & & \\
\hline
\end{tabular}

\subsection{EPFL high fluid pressure triaxial cell}

The EPFL high fluid pressure triaxial cell with an axis translation configuration presented in [35] was used. Fig. 1 shows the schematic illustration of the triaxial cell and the connected volume pressure controllers (VPC). Axial confining stress up to $80 \mathrm{MPa}$ can be applied by a hydraulic jack, while radial confining stress up to 64 $\mathrm{MPa}$ can be applied by confining oil. Water pressure and gas pressure are applied on the upstream and downstream sides, respectively. Compressed nitrogen gas is injected, while the maximum gas pressure is 20 MPa. Fig. 1. (b) shows the detailed configuration. The filter will be placed just below the sample, ensuring good contact and continuity of the water phase. A base pedestal is equipped with a spiral channel for regular flushing. In the tests presented in this paper, a steel dummy sample was used instead of the sample shown.

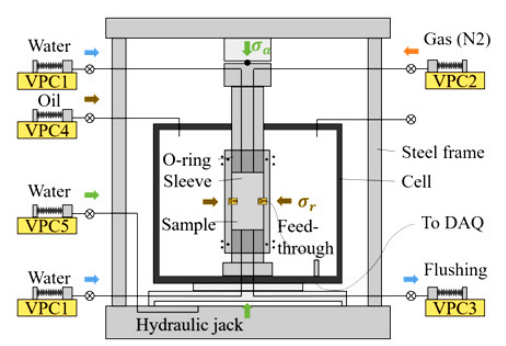

(a)

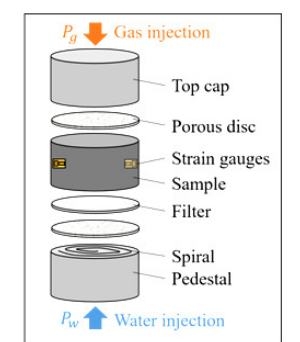

(b)
Fig. 1. (a) Schematic illustration of the cell [35] and (b) detailed view of the axis translation configuration.

\subsection{Saturating filters}

All filter candidates were saturated by deionized, deaerated water. Ceramic Discs were saturated by capillarity outside the cell. Membrane XT was supplied with preservatives, so it was first rinsed and immersed in water. Shale Disc was saturated in the cell in a quasiisochoric condition in a similar way described in [37]; confining stress was increased after water injection such that the swelling deformation did not exceed $-0.1 \%$. In all cases, the remaining air in the system was removed by a vacuum pump after the cell assembly. Full saturation was further ensured by inducing water flow that would help flush small air bubbles in the filter.

\subsection{Experimental procedure}

The experimental campaign was carried out in 4 steps: 1) permeability test, 2) water displacement, 3) diffusion test, and 4) gas breakthrough test. Fig. 2. (a) provides a schematic illustration of the applied fluid pressures and typical flow rate trends in each step. The gas breakthrough test results were analyzed by a plotting flow rate against differential pressure such as Fig. 2. (b)

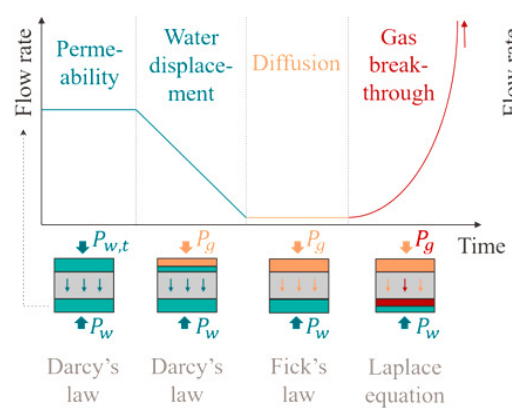

(a)

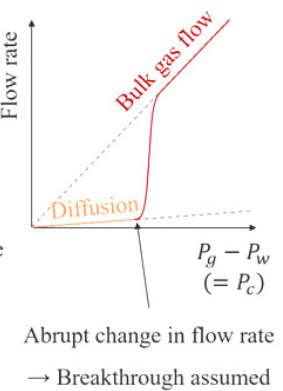

(b)
Fig. 2. (a) Experimental procedure in 4 steps showing the applied pressure and typical flow rate trends and (b) analysis of the gas breakthrough test results. 
First, a hydraulic pressure gradient was applied by increasing the water pressure on the downstream side. When a steady-state condition was attained, the water volume exiting the filter was recorded in the bottom reservoir at a constant pressure. For Membrane XT, this was done at multiple confining stress levels to study the permeability loss due to membrane compaction. The final water pressure was always $2 \mathrm{MPa}$.

$\mathrm{T}$ residual water remained in the system after the permeability test and had to be removed. For Ceramic Discs and Membrane XT, a gas pressure (3 MPa) higher than the water pressure (2 $\mathrm{MPa})$ was applied on the downstream side to push the residual water across the filter. This was practically impossible for Shale Disc since the flow rate was too low. Thus, the cell was dismantled to remove the remaining water in the system and was carefully reassembled with a dry porous disc.

Once the gas front reached the surface of the filter, the viscous gas flow was prohibited by capillary sealing. This could be observed by a very small flow rate compared to the water flow in the previous stage. Diffusion flow can occur through the water phase in the filter at a constant rate. This process can be explained by Fick's law, which describes the mass diffusion driven by a concentration gradient. The diffusion flow rate was measured at the bottom reservoir at constant pressure.

Lastly, the gas pressure was increased progressively until a clear gas breakthrough was observed. Initially, an almost linear increase in flow rate was measured due to the increase of diffusion flow as the concentration gradient increased. When the applied differential pressure reached a threshold value, the onset of viscous gas flow was detected by an abrupt change in flow rate as illustrated in Fig. 2. (b).

\section{Experimental results}

\subsection{Membrane compaction}

The PES membranes used in this study, or any polymeric membranes in general, have very low mechanical strength compared to typical geomaterials. Even when a few hundreds of $\mathrm{kPa}$ of external stress is applied, they are susceptible to large irreversible deformation and result in a permanent decrease in flux. This behavior is known as "membrane compaction" and has been studied within the membrane community [38,39] although the largest applied stress was limited to $0.7 \mathrm{MPa}$.

Given that confining stress for gas shale testing can be higher (several tens of MPa), it is important to ensure that the membranes are mechanically compatible and always permeable to water. Several PES membranes not presented in this paper were tested following the same procedure with the maximum isotropic confining stress of $15 \mathrm{MPa}$. Very large deformation was observed; the measured axial strains after the test were $18-20 \%$. Besides, membranes adjacent to the porous discs were found to be crushed by the rugged surface of the porous discs. This significantly compromised the membrane integrity and resulted in a gas breakthrough pressure much below the expected value. For Membrane XT, it was alleviated by stacking 30 layers. Only a few layers adjacent to the porous disc were found damaged while the rest was not. The measured axial strain was $25 \%$, which corresponds to $1.4 \mathrm{~mm}$ of vertical settlement. This result highlighted that the settlement of membranes must be considered if they were selected.

\subsection{Permeability}

Permeability is an important indicator for estimating equilibrium time in an axis translation apparatus. The permeability $k$ was calculated by Darcy's law, neglecting the difference in elevation of the two bases:

$$
d V_{w} / d t=k A\left(P_{w, t}-P_{w}\right) / \mu / t_{f}
$$

where $d V_{w} / d t$ is the water flow rate in steady-state conditions, $k$ is the intrinsic permeability, $A$ is the crosssectional area of the filter, $\mu$ is the viscosity of water, $P_{w, t}$ is the water pressure at the top reservoir, $P_{w}$ is the water pressure at measuring system at the bottom reservoir, and $t_{f}$ is the thickness of the filter.

Fig. 3. shows the measured permeability against applied isotropic confining stress. Membrane XT had a permeability in the order of $10^{-16} \mathrm{~m}^{2}$ under $1 \mathrm{MPa}$ of isotropic confining stress. As the confining stress increased, the permeability decreased non-linearly by almost two orders of magnitude. Ceramic Discs A showed the highest permeability in the order of $10^{-17} \mathrm{~m}^{2}$, while Ceramic Discs B showed a value lower by an order of magnitude. This indicates that the $\mathrm{Al}_{2} \mathrm{O}_{3}$ coating on Ceramic Disc B provided small pores on the surface. Shale Disc showed a much lower permeability in the $\mathrm{nD}$ range. Considering the typical shales have permeability in the range between $\mathrm{nD}$ to $100 \mathrm{nD}$, only Shale Disc has a permeability comparable to that of a gas shale sample.

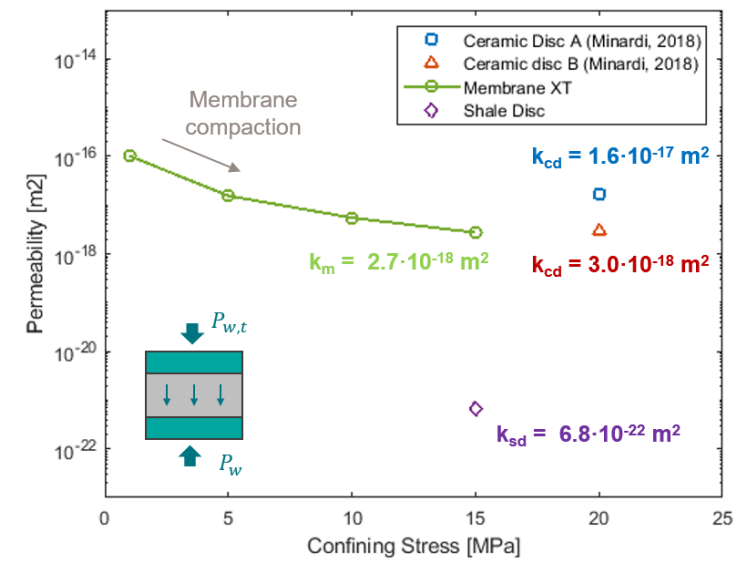

Fig. 3. Measured permeability of the filter candidates.

\subsection{Diffusion coefficient}

Quantifying diffused gas volume is necessary to track water volume changes for equilibrium. The diffusion coefficient $D$ can be calculated by the following equation $[25,40]$ :

$$
d V_{d} d t=n A D h\left(P_{g}-P_{w}\right) /\left(P_{w}+P_{a t m}\right) / t_{f}
$$


where $d V_{d} / d t$ is the measured diffusion flow rate, $n$ is the porosity of the filter, $D$ is the diffusion coefficient, $h$ is the volumetric solubility coefficient, and $P_{a t m}$ is the atmospheric pressure $(101 \mathrm{kPa})$.

Fig. 4. shows the diffusion coefficients of the filter candidates along with those for ceramic discs collected from the literature [25-27]. Both Ceramic Discs showed diffusion coefficients consistent with the results in [27]. Membrane XT showed a large diffusion coefficient, consistent with high values for CA membranes [10]. Shale Disc showed the lowest diffusion coefficient among the candidates. Another observation is that diffusion coefficients decreased with a soil sample (with *). Likewise, if an actual sample is placed on the filter, a diffusion rate lower than the measured value is expected.

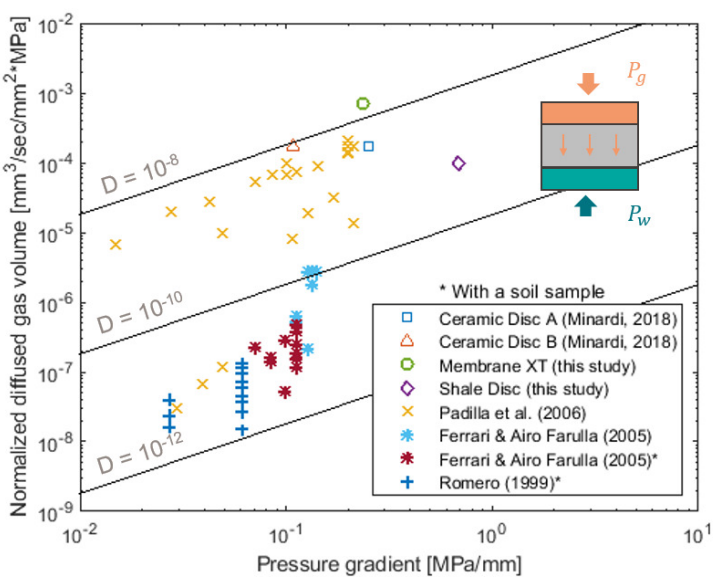

Fig. 4. Diffusion coefficients of HAEV filters.

\subsection{Gas breakthrough pressure}

The most critical parameter to evaluate the suitability of a filter is the gas breakthrough pressure or the differential pressure when the breakthrough occurs. A gas breakthrough was assumed when an abrupt change in flow rate was observed. Fig. 5. shows the measured flow rate against the applied differential pressure. Ceramic Disc A and B showed a breakthrough at 3.8 MPa and 4.2 $\mathrm{MPa}$. Membrane XT showed a breakthrough at 6.3 MPa. For Shale Disc, no clear sign of breakthrough was observed at $11 \mathrm{MPa}$ of differential pressure.

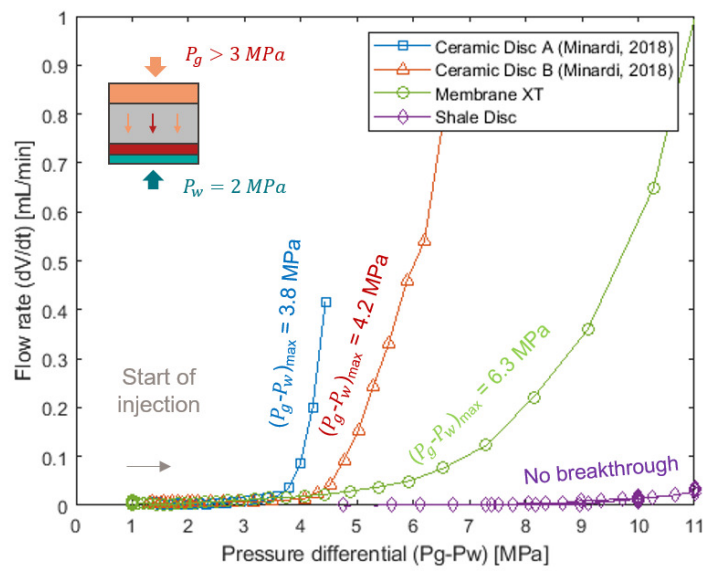

Fig. 5. Results of the gas breakthrough tests.

\section{Summary and Discussions}

A high capacity axis translation apparatus for gas shale testing requires a filter that can sustain high differential pressure, at least $10 \mathrm{MPa}$. Currently, the upper limit of the capillary pressure in conventional axis translation apparatuses is quite limited. Few published results reported maximum capillary pressure values higher than 1.5 $\mathrm{MPa}$ of conventional ceramic discs.

We evaluated the performances of four HAEV filter candidates, including the two ceramic discs tested by [35], by measuring the permeability, diffusion coefficient, and gas breakthrough pressure in a triaxial stress condition. Ceramic Disc A, Ceramic Disc B, and Membrane XT showed gas breakthroughs at 3.8, 4.2, and 6.3 $\mathrm{MPa}$ of differential pressure, respectively. Shale Disc gave the best result without a sign of breakthrough at 11 $\mathrm{MPa}$ of differential pressure.

Fig. 6 showcases the expected capacities of all four filter candidates. The capillary pressure ranges were superposed on the water retention curve (main drying path) of a gas shale sample reported in [9]. Note that the capillary pressure was computed from the pore size distribution result obtained by mercury intrusion porosimetry (MIP), assuming 0 degrees of contact angle. Based on Fig. 6, Shale Disc will allow bringing a similar gas shale core sample to partially saturated conditions approximately to $85 \%$. If contact angle different than 0 degrees for gas shales [41] is used, a lower degree of saturation may be achieved.

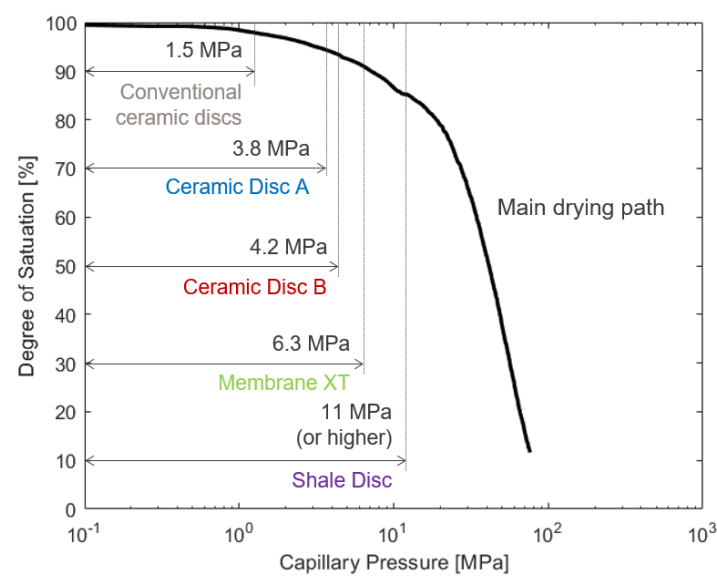

Fig. 6. Capillary pressure ranges of the tested filter candidates superposed on the water retention curve of a gas shale core sample [9].

Diffused gas bubbles accumulating under the filter will become a challenge at high differential pressure. Considering the small native water content of gas shales and relatively high diffusion flow rate due to the high differential pressure, the tracking of water volume changes during equilibrium will be complicated. A new device similar to Fredlund's diffused air volume indicator [40] may have to be designed to precisely measure the diffused gas volume. Besides, Shale Disc will provide the highest capillary pressure among the filter candidates but will require a very long equilibrium time due to the low permeability. 
Developing a high capacity axis translation apparatus is of great importance to experimentally study the mechanical response of gas shales to capillary pressure and saturation changes. Future research will investigate the effective stress that can describe the volumetric deformation of partially saturated gas shales.

\section{References}

1. R. W. J. Edwards and M. A. Celia, Water Resour. Res. 54, 3196 (2018)

2. P. Cheng, H. Tian, X. Xiao, H. Gai, T. Li, and X. Wang, Energy and Fuels 31, 13120 (2017)

3. K. Makhanov, A. Habibi, H. Dehghanpour, and E. Kuru, J. Unconv. Oil Gas Resour. 7, 22 (2014)

4. R. T. Ewy, Acta Geotech. 9, 869 (2014)

5. G. E. King, in SPE Hydraul. Fract. Technol. Conf. (2012), pp. 1-80

6. L. T. Bryndzia, in 3rd EAGE Shale Work. Shale Phys. Shale Chem. (2012), pp. 23-25

7. M. Lal, in SPE Lat. Am. Caribb. Pet. Eng. Conf. (1999)

8. J. Shaoul, L. Van Zelm, and C. J. De Pater, in SPE Middle East Unconv. Gas Conf. Exhib. (2011), pp. 388-400

9. A. Ferrari, A. Minardi, R. Ewy, and L. Laloui, Int. J. Rock Mech. Min. Sci. 107, 110 (2018)

10. E. Romero, in Proc. $4^{o}$ Simpósio Bras. Solos Nâo Saturados, edited by W. Y. Y. Gehling and F. Schnaid (Porto Alegre, Brazil, 2001), pp. 535-542

11. A. Minardi, A. Ferrari, R. Ewy, and L. Laloui, Rock Mech. Rock Eng. 51, 1967 (2018)

12. A. Minardi, A. Ferrari, R. Ewy, and L. Laloui, J. Nat. Gas Sci. Eng. 49, 132 (2018)

13. J. W. Hilf, An Investigation of Pore Water Pressure in Compacted Cohesive Soils, University of Colorado, 1956

14. M. D. Zoback and A. H. Kohli, Unconventional Reservoir Geomechanics (Cambridge University Press, 2019)

15. A. Tarantino, in Mech. Unsaturated Geomaterials (2010), pp. 1-36

16. M. Tuller, O. Dani, and L. M. Dudley, Water Resour. Res. 35, 1949 (1999)

17. T. Engelder, L. M. Cathles, and L. T. Bryndzia, J. Unconv. Oil Gas Resour. 7, 33 (2014)

18. P. Delage, E. Romero, and A. Tarantino, in Proc. $1 s t$ Eur. Conf. Unsaturated Soils (2008), pp. 33-52

19. F. A. M. Marinho and R. J. Chandler, Géotechnique 43, 551 (1993)

20. F. A. M. Marinho, W. A. Take, and A. Tarantino, Lab. F. Test. Unsaturated Soils 3 (2009)

21. S. K. Vanapalli, M. V. Nicotera, and R. S. Sharma, Lab. F. Test. Unsaturated Soils 26, 33 (2009)

22. A. W. T. Bishop and I. B. Donald, in 5th Int. Conf. Soil Mech. Found. Eng. (1961), pp. 13-21
23. A. Tarantino, L. Mongiovì, and G. Bosco, Géotechnique 50, 275 (2000)

24. C. Zhang and N. Lu, Rev. Geophys. 56, 532 (2018)

25. E. M. Romero, Characterization and ThermoHydromechanical Behaviour of Unsaturated Boom Clay, UPC Barcelona, 1999

26. C. Airo Farulla and A. Ferrari, in Proc. an Int. Symp. Adv. Exp. Unsaturated Soil Mech., edited by A. Tarantino, E. Romero, and Y. J. Cui (Trento, Italy, 2005), pp. 43-48

27. J. M. Padilla, Y. Y. Perera, W. N. Houston, N. Perez, and D. G. Fredlund, in Unsaturated Soils 2006 (2006), pp. 1852-1863

28. A. Lloret, M. V. Villar, M. Sánchez, A. Gens, X. Pintado, and E. E. Alonso, Géotechnique 53, 27 (2003)

29. E. Romero, M. V. Villar, and A. Lloret, Eng. Geol. 81, 255 (2005)

30. T. Nishiumura, J. Koseki, D. G. Fredlund, and H. Rahardjo, Geotech. Test. J. 35, (2012)

31. W. T. Hong, Y. S. Jung, S. Kang, and J. S. Lee, Materials (Basel). 9, (2016)

32. J. Mendes and O. Buzzi, Can. Geotech. J. 50, 550 (2013)

33. J. Mendes, D. Gallipoli, A. Tarantino, and D. Toll, Géotechnique (2016)

34. R. Monroy, A. Ridley, K. Dineen, and L. Zdravkovic, Geotech. Test. J. 30, 220 (2007)

35. A. Minardi, Hydro-Mechanical Characterization of Gas Shales and Opalinus Clay Shale in Partially Saturated Conditions, EPFL, 2018

36. U. Kuila, D. K. McCarty, A. Derkowski, T. B. Fischer, and M. Prasad, Fuel 117, 1115 (2014)

37. E. Crisci, A. Ferrari, S. B. Giger, and L. Laloui, Eng. Geol. 251, 214 (2019)

38. K. M. Persson, V. Gekas, and G. Trägårdh, J. Memb. Sci. 100, 155 (1995)

39. S. Stade, M. Kallioinen, A. Mikkola, T. Tuuva, and M. Mänttäri, Sep. Purif. Technol. 118, 127 (2013)

40. D. G. Fredlund and RahrdjoH., Soil Mechanics for Unsaturated Soils (John Wiley \& Sons, Inc., New York, NY, United States, 1993)

41. M. A. Q. Siddiqui, S. Ali, H. Fei, and H. Roshan, Earth-Science Rev. 181, 1 (2018) 